\title{
Expression of Pseudorabies Virus (PRV) Glycoproteins gB, gC and gD using Bacterial Expression System
}

\author{
Bit Na Rae Yun, Sung Min Bae, Jun Beom Lee, Hee Jung Kim, and Soo Dong Woo* \\ Department of Agricultural Biology, College of Agriculture, Life \& Environment Science, Chungbuk National University, \\ Cheongju 361-763, Korea
}

(Received 26 August 2011; Accepted 8 September 2011)

The Pseudorabies (PR), also called Aujeszky's disease (AD), is an infectious viral disease caused by an alpha herpes virus and has domestic and wild pigs, as well as a wide range of domestic and wild animals, as the natural host. Pseudorabies virus (PRV) virions contain several envelope glycoproteins. Among them, gB, gC and gD are regarded as the major immunogenic proteins. We expressed these glycoproteins using the bacterial expression system and analyzed recombinant proteins. Expression of glycoproteins gC and gD were observed on SDS-PAGE or Western blot analysis, but gB was not. Optimal concentration of IPTG and inducing time were determined as $1.0 \mathrm{mM}$ and $4 \mathrm{~h}$, respectively, for the expression of both $\mathrm{gC}$ and $\mathrm{gD}$ in $\boldsymbol{E}$. coli. A sodium dodecyl sulfate (SDS) was the most efficient detergent in solubilizing insoluble recombinant protein.

Key words: Pseudorabies virus, Glycoproteins gB, gC and $\mathrm{gD}$, Bacterial expression system

\section{Introduction}

Pseudorabies or Aujeszky's disease (AD), caused by pseudorabies virus (PRV), is a serious illness of pigs and makes significant economic losses in the pig industry (Hong et al., 2002). PRV virions contain several envelope glycoproteins which are important for interactions between viral particles and host cells and act as major targets for

\footnotetext{
*To whom the correspondence addressed

Department of Agricultural Biology, College of Agriculture, Life \& Environment Science, Chungbuk National University, Cheongju 361-763, Korea.

Tel: +82-43-261-2553; Fax: +82-43-271-4414;

E-mail: sdwoo@cbnu.ac.kr
}

the immune responses of the infected animals. Glycoproteins $\mathrm{gB}, \mathrm{gC}$ and $\mathrm{gD}$ are regarded as the major immunogenic proteins and the antibodies induced by them can neutralize virus in vitro or in vivo (Mettenleiter, 1994; 1996). Attempts to control AD in swine include vaccination with killed or live virus vaccines and passive immunization with hyperimmune serum (Hsu et al., 1984). And several immunogenic proteins use to development vaccines. However, PRV glycoproteins have transmembrane domain and the cell-based expression of these membrane proteins is difficult (Katzen et al., 2009). Our recent report also indicated this fact, and the expression efficiency was not satisfied (Koo et al., 2011).

Bacterial expression system is most popular and frequently used to produce recombinant proteins (Le et al., 2009). E.coli can grow rapidly to high cell densities, and strains used for recombinant protein production have been genetically modified and high-level expression of recombinant proteins. Expression of the recombinant proteins depends on the various culture conditions and recombinant expression plasmids require a strong transcriptional promoter to control high-level gene expression. However, high-level expression of recombinant proteins in E.coli often precipitates into insoluble aggregates called inclusion bodies that are, in general, misfolded proteins and thus biologically inactive (Singh et al., 2005; RabhiEssafi et al., 2007). Insoluble proteins are devoid of biological activity and need solubilization, refolding and purification procedures to recover functionally bioactive product. In general, effective solubilization of insoluble proteins requires appropriate detergents or chaotropic agents. This often results in a very low recovery of the refolded protein (Song et al., 2009).

In this study, we tried to express PRV glycoproteins using pET vector in E.coli and characterized recombinant proteins because there is little report about the expression of these in bacterial system. Furthermore, we determined 
Table 1. Primers used for amplification of the PRV genome

\begin{tabular}{|c|c|}
\hline Primer & Nucleotide sequence $^{a}$ \\
\hline gB-F & $\begin{array}{c}5^{\prime} \text { - GGA TCC ATG CCC GCT GGT GGC GGT } \\
\text { CTT - 3, }\end{array}$ \\
\hline gB-R & 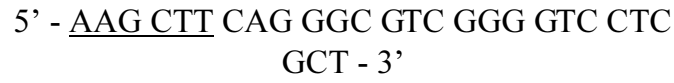 \\
\hline $\mathrm{gC}-\mathrm{F}$ & 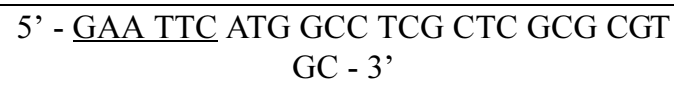 \\
\hline $\mathrm{gC}-\mathrm{R}$ & 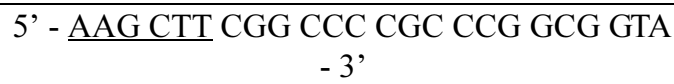 \\
\hline $\mathrm{gD}-\mathrm{F}$ & $\begin{array}{c}5^{\prime} \text { - GGA TCC ATG CTG CTC GCA GCG CTA } \\
\text { TTG - 3, }\end{array}$ \\
\hline $\mathrm{gD}-\mathrm{R}$ & 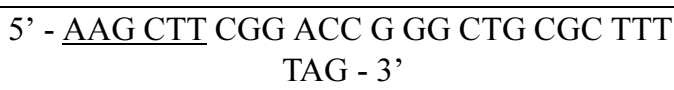 \\
\hline
\end{tabular}

${ }^{a}$ Restriction sites are underlined.

the optimal solubilizing detergent for the expressed insoluble recombinant proteins through comparing several detergents.

\section{Materials and Methods}

\section{Construction of the expression plasmid}

The primers used for PCR amplification are listed in Table 1. The purified each PCR products were cloned into the T\&A cloning vector and then digested with BamHI $(E c o$ RI) and HindIII restriction enzymes and inserted into the pET-21a $(+)$ expression vector (Fig. 1). Expression plasmids were named $\mathrm{pET}-\mathrm{gB},-\mathrm{gC}$ and $-\mathrm{gD}$, respectively. Sequencing and the restriction enzyme digestion confirmed that the cloning was successful.

\section{Expression of the PRV glycoproteins in E.coli}

Escherichia coli BL21 (DE3) cells were transformed with $\mathrm{pET}-\mathrm{gB},-\mathrm{gC}$ and $-\mathrm{gD}$. A single colony from the transformants was added into LB medium containing ampicillin. This was cultured to an optical density $\left(\mathrm{OD}_{600}\right)$ of 0.6 and then $1.5 \mathrm{ml}$ of the culture medium was added to $30 \mathrm{ml} \mathrm{LB}$ medium containing ampicillin and further incubated at $37^{\circ} \mathrm{C}$ up to an $\mathrm{OD}_{600}$ of 1.0 , then isopropyl $\beta$-D1-thiogalactopyranoside (IPTG) was added to induce protein expression. Cells were harvested by centrifugation at
$10,000 \mathrm{~g}$ for $10 \mathrm{~min}$ and washed with PBS, resuspended in lysis buffer $(50 \mathrm{mM}$ Tris-HCl, $5 \%$ glycerol, $50 \mathrm{mM} \mathrm{NaCl}$, $\mathrm{pH}$ 7-8). The resuspended cells were lysed by sonication and mixed with protein sample buffer and boiled. Protein samples were analyzed by SDS-PAGE and Western blotting.

\section{RT-PCR}

A total RNA was extracted from induced cell with Easy$\operatorname{spin}^{\mathrm{TM}}$ Total RNA Extraction Kit (iNtRON Biotechnology, Korea) as recommended by the manufacturer. The RNA was used as a template for cDNA synthesis using Maxime RT Premix Kit (iNtRON Biotechnology, Korea). PCR amplification was performed using AccuPower PCR Premix (Bioneer Co., Korea). Primers used for PCR amplification are listed in Table 1. The amplified PCR products were separated by electrophoresis in $1.0 \%$ agarose gel.

\section{Optimization of expression conditions}

Different concentrations of IPTG $(0.5,1.0,1.5,2.0$ and $2.5 \mathrm{mM}$ ) were added into the growing bacterial culture to determine the optimal concentration of IPTG for protein induction. As $1.0 \mathrm{mM}$ IPTG was found to be the optimal concentration, it was added in bacterial culture and growth was analyzed for $24 \mathrm{~h}$ at $4 \mathrm{~h}$ interval $(0,4,8,12$, 16,20 and $24 \mathrm{~h}$ ).

\section{Solubilization of recombinant proteins}

Various detergents such as Nonidet P-40 (NP-40), Triton X100, Tween 20, Tween 80 and sodium dodecyl sulfate (SDS) were prepared. Cells were resuspended in lysis buffer, and then incubated in ice for $1 \mathrm{~h}$ with the detergents at $1 \%(\mathrm{w} / \mathrm{v})$. After incubation, insoluble fractions were collected by centrifuged at $16,000 \mathrm{~g}$ for $10 \mathrm{~min}$ at $4^{\circ} \mathrm{C}$. Total, soluble fractions (supernatant) and insoluble fractions (pellet) were analyzed by SDS-PAGE and Western blotting.

\section{Results and Discussion}

\section{Expression of PRV glycoproteins}

Expression of the PRV glycoproteins in E.coli was analyzed by SDS-PAGE, Western blotting and RT-PCR.

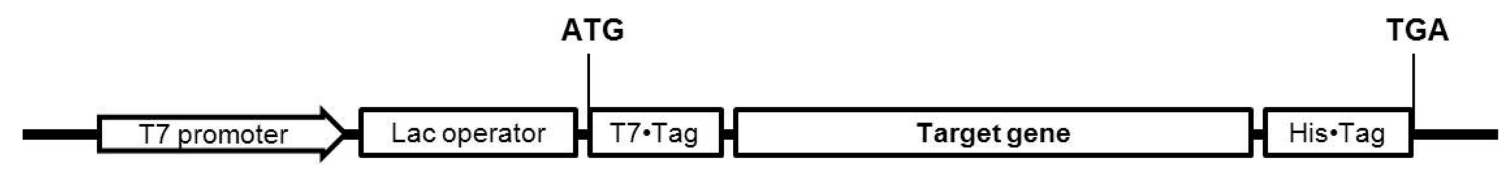

Fig. 1. Structure of the expression plasmid. Each genes were cloned between the BamHI (EcoRI) and HindIII of pET-21a(+), downstream of the sequence coding the His-tag and expression plasmid under the control of the T7 promoter. 

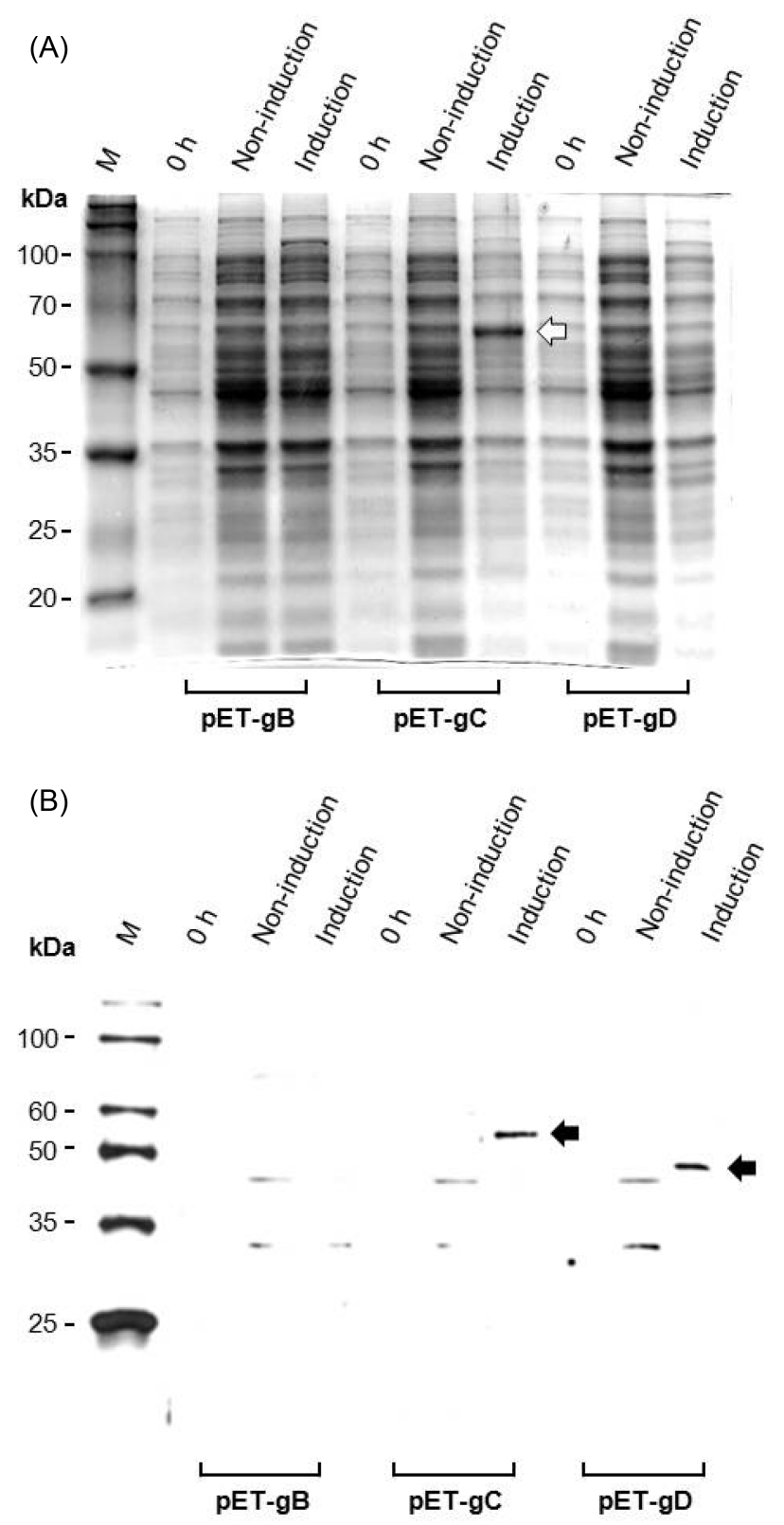

Fig. 2. Expression of glycoproteins $\mathrm{gB}, \mathrm{gC}$ and $\mathrm{gD}$ in E.coli. The cells culture was induced with $1.0 \mathrm{mM}$ IPTG and incubated for $8 \mathrm{~h}$ at $37^{\circ} \mathrm{C}$. The cell pellets washed once with PBS, and lysed in lysis buffer. Proteins were separated on a $10 \%$ SDS-PAGE (A), transferred to nitrocellulose membranes for Western blot analysis and reacted with anti-His monoclonal antibody (B). Glycoproteins $\mathrm{gC}$ and $\mathrm{gD}$ are indicated with arrowheads.

Using Coomassie blue staining, detection was difficult except for the glycoprotein $\mathrm{gC}$ (Fig. 2A). To confirm the presence of expressed proteins, the total proteins were transferred to nitrocellulose and analyzed by immunoblotting using anti-His monoclonal antibody (Fig. 2B). The

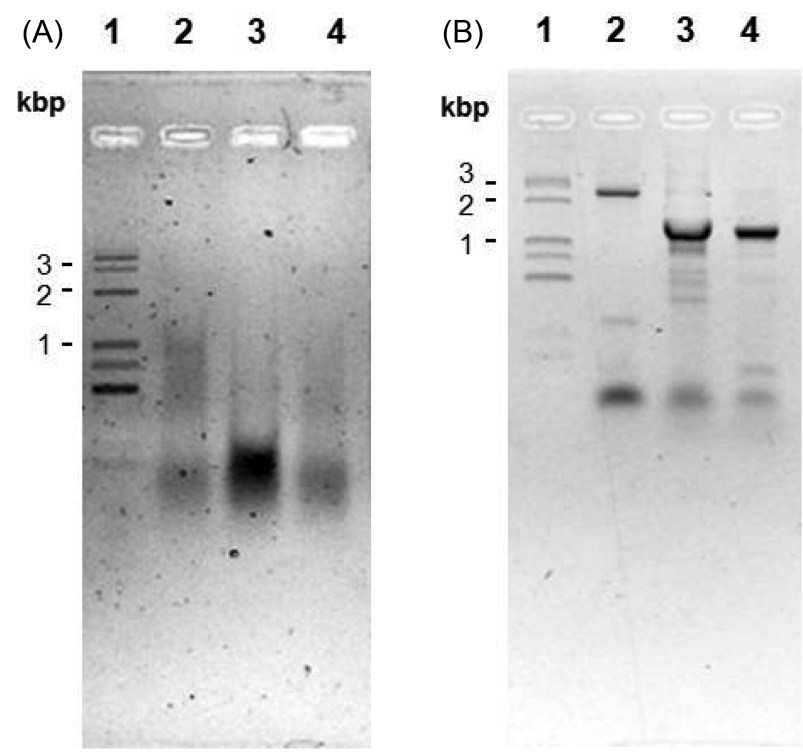

Fig. 3. Agarose gel electrophoresis analysis of RNA extraction products (A) and RT-PCR products (B) of PRV glycoprotein genes. Lane 1, DNA maker; Lane 2, gB; Lane 3, gC; Lane 4, gD.

glycoproteins $\mathrm{gC}$ and $\mathrm{gD}$ were detected at approximately 55 and $45 \mathrm{kDa}$, respectively, with one band but $\mathrm{gB}$ was not on Western blot analysis. To elucidate the reason for none or low expression of target proteins, we checked whether target genes were transcribed to mRNA or not by RT-PCR. Extracted RNA from induced cells were confirmed by electrophoresis on 1.0\% agarose gel (Fig. 3A), and then we used them for RT-PCR. The RT-PCR products of glycoproteins $\mathrm{gB}, \mathrm{gC}$ and $\mathrm{gD}$ could be detected by agarose gel electrophoresis were approximately $2.7,1.4$ and $1.2 \mathrm{~Kb}$, respectively, corresponding to the expected sizes (Fig. 3B). This may suggest that low or none expression of PRV glycoproteins are not associated to the transcription but to the translation process. Expression of recombinant proteins in E.coli is generally difficult when the codon use in the recombinant gene differs from the codon use in the host cells. Also, high-level expression is lead to accumulation as inclusion bodies in E.coli, insoluble proteins formed results as high-level expression of recombinant proteins. Insoluble proteins are difficult to detection because not solubilized in lysis buffer. In this case, solubilization of insoluble proteins requires appropriate chaotropic agents or detergents (Singh et al., 2005). Therefore, in the case of low expression level, we are able to optimizing the codon usage in the gene to match E.coli codon bias or to solubilizing the recombinant proteins.

Optimal expression conditions

For the maximal expression of PRV glycoproteins, the 

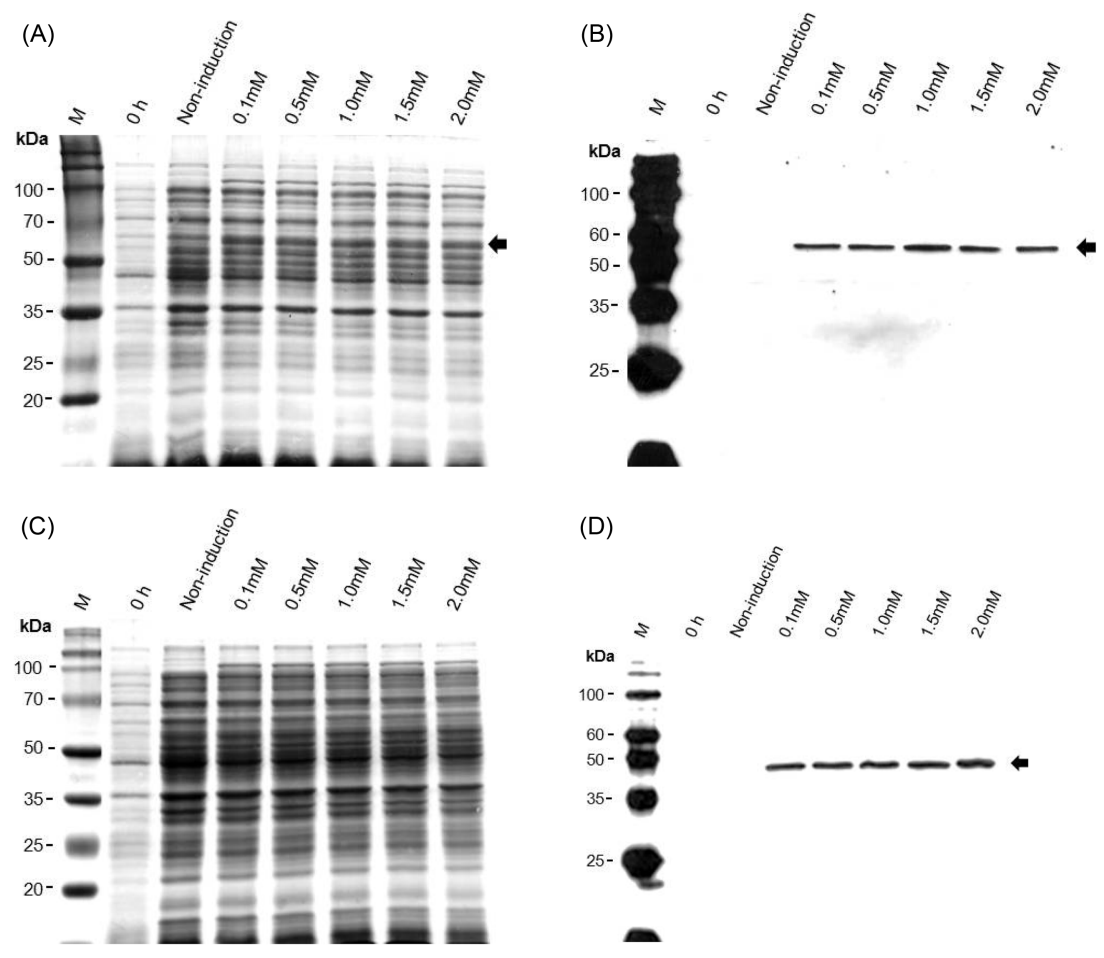

Fig. 4. IPTG concentration analysis of glycoprotein $\mathrm{gC}(\mathrm{A}, \mathrm{B}), \mathrm{gD}(\mathrm{C}, \mathrm{D})$ expression in E.coli. The cells culture was induced with various concentration of IPTG $(0.5 \sim 2.5 \mathrm{mM})$ and incubated for $8 \mathrm{~h}$ at $37^{\circ} \mathrm{C}$. Proteins were separated on a $10 \%$ SDS-PAGE (A, C), transferred to nitrocellulose membranes for Western blot analysis and reacted with anti-His monoclonal antibody (B, D). Glycoproteins $\mathrm{gC}$ and $\mathrm{gD}$ are indicated with arrowheads.
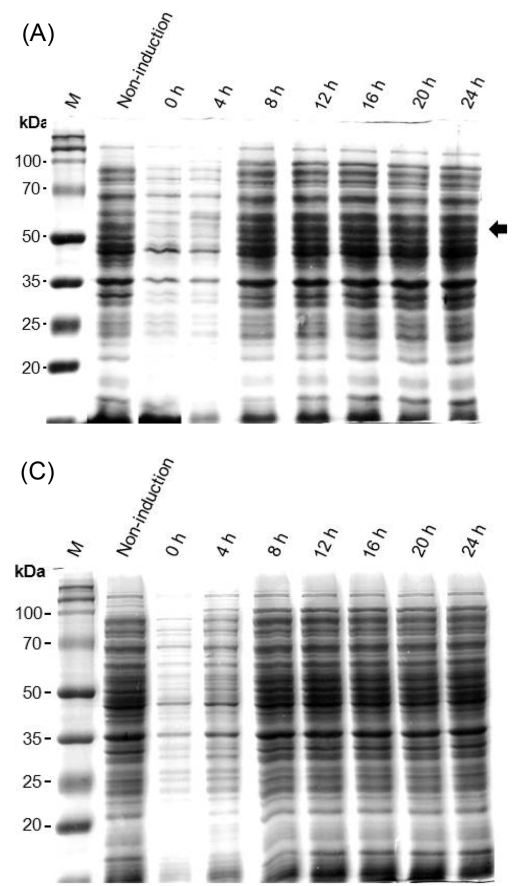

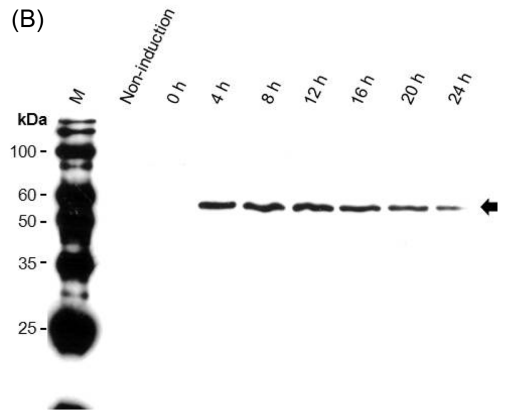

(D)

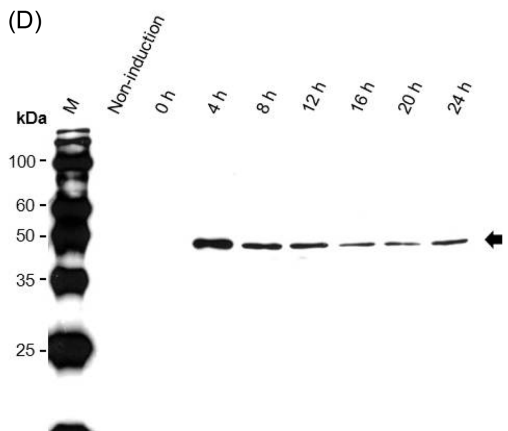

Fig. 5. Time course analysis of the glycoprotein $\mathrm{gC}(\mathrm{A}, \mathrm{B}), \mathrm{gD}(\mathrm{C}, \mathrm{D})$ expression in E.coli. The cells culture was induced with $1.0 \mathrm{mM}$ and incubated for various times (0 24 hours). Proteins were separated on a 10\% SDS-PAGE (A, C), transferred to nitrocellulose membranes for Western blot analysis and reacted with anti-His monoclonal antibody (B, D). Glycoproteins $\mathrm{gC}$ and $\mathrm{gD}$ are indicated with arrowheads. 

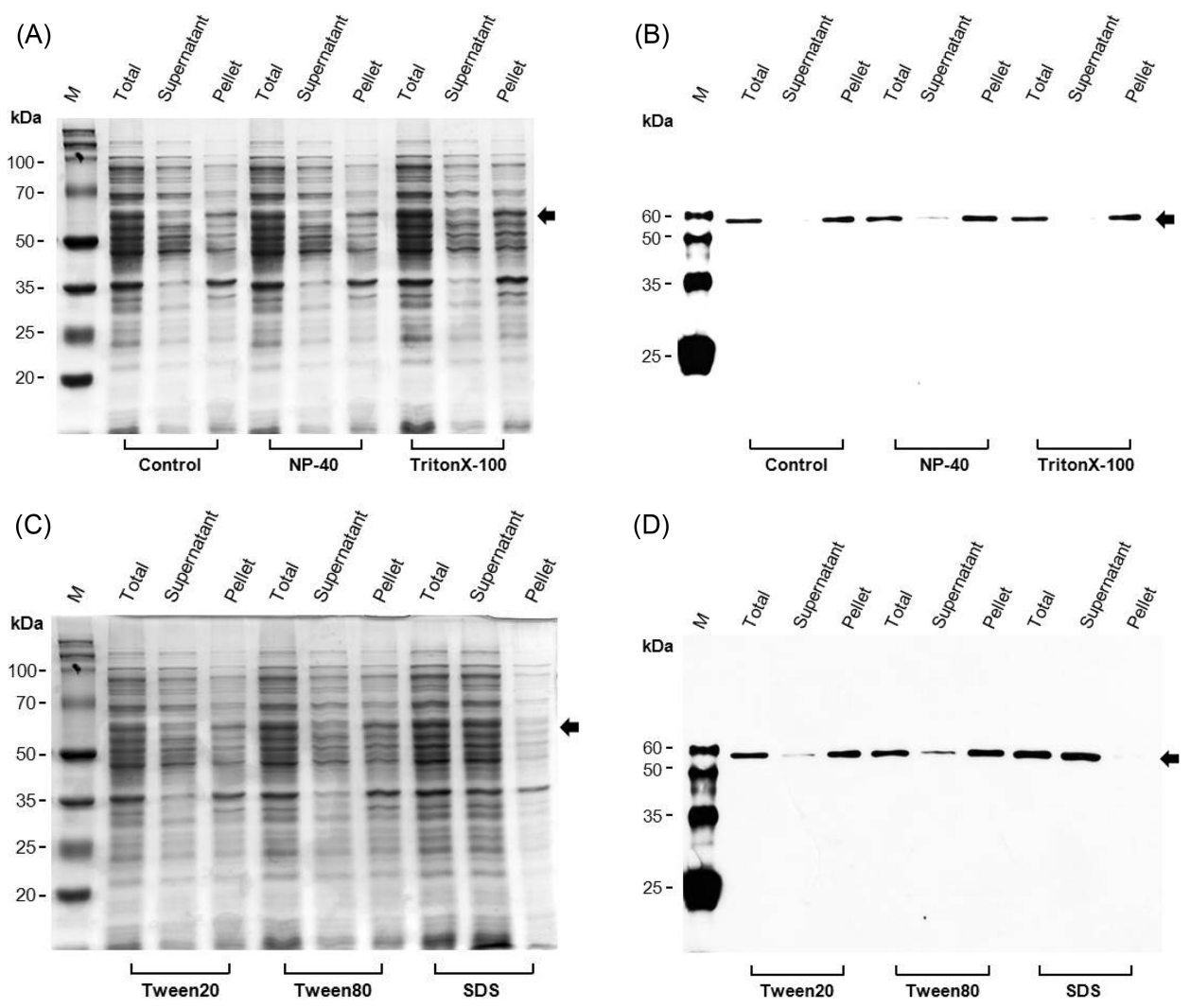

(D)
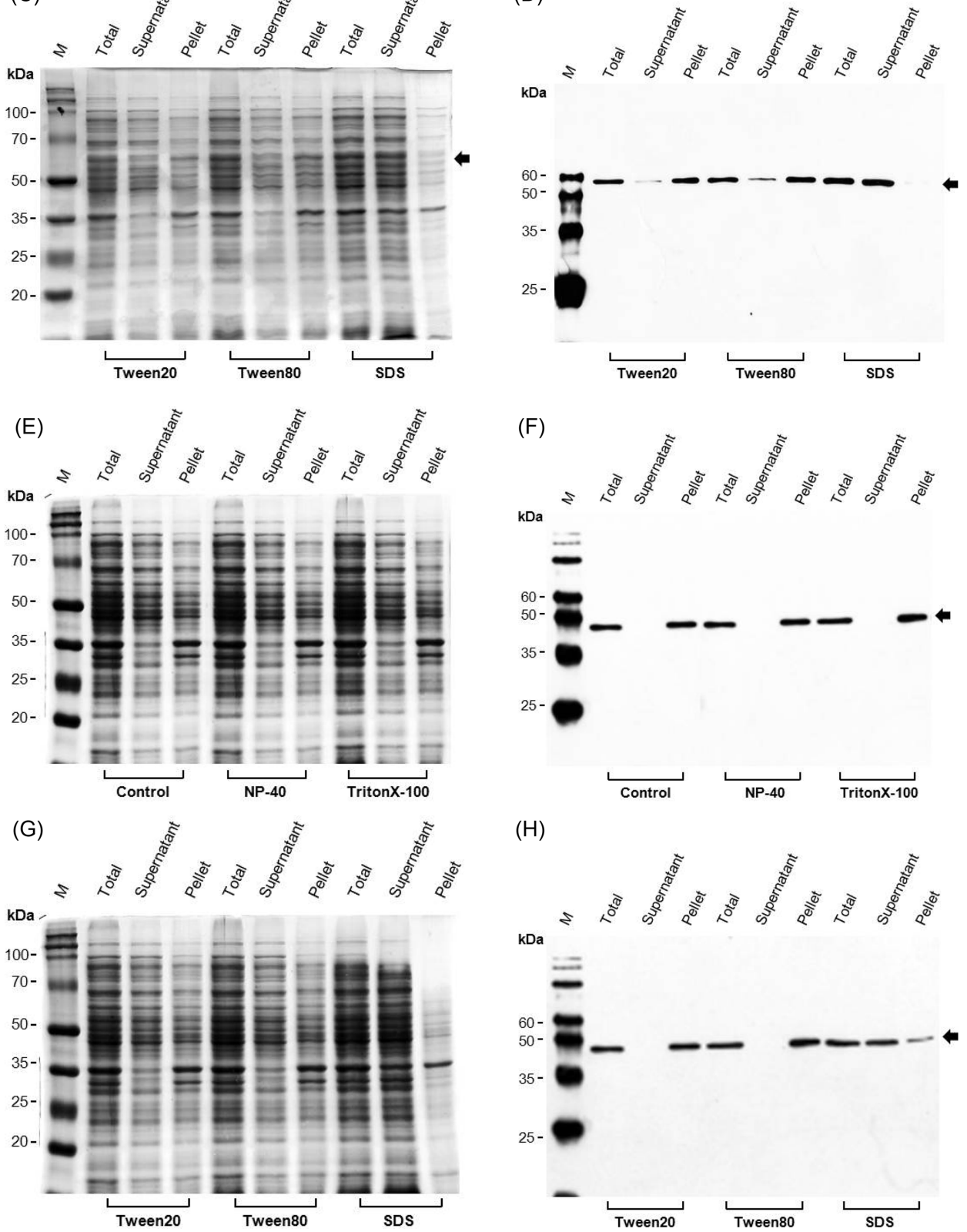

Fig. 6. Effect of various detergents (gC, A-D; gD, E-H). Proteins were separated on a 10\% SDS-PAGE (A, C, E, G), transferred to nitrocellulose membranes for Western blot analysis and reacted with anti-His monoclonal antibody $(\mathrm{B}, \mathrm{D}, \mathrm{F}, \mathrm{H})$. 
optimal IPTG concentration and inducing time were determined. Although $1.0 \mathrm{mM}$ concentration of IPTG appeared highest expression for both glycoproteins, the concentration of IPTG may be immaterial to the expression level (Fig. 4). Expression of glycoproteins $\mathrm{gC}$ and $\mathrm{gD}$ appeared to start at $4 \mathrm{~h}$ post-induction, no further increase after $4 \mathrm{~h}$ post-induction in our experiments (Fig. 5). The results assumed that PRV glycoproteins were not accumulated during the expression time and glycoproteins were degraded. It is known that recombinant protein synthesis in the pET system would be too rapid for protein expression (Semba et al., 2008). As expected, we observed that PRV glycoproteins expressed rapidly. As a result, optimal inducing time was determined as $4 \mathrm{~h}$ for the expression of both $\mathrm{gC}$ and $\mathrm{gD}$ in E. coli.

\section{Solubilizing detergent}

The presence of PRV glycoproteins in both the soluble (supernatant) and insoluble fractions (pellet) was confirmed by SDS-PAGE and Western blotting. The PRV glycoproteins were present in insoluble fractions (Fig. 6). Expression of recombinant proteins in E.coli often results in accumulating then as insoluble aggregates in vivo. To avoid protein aggregation, E.coli is to lower the cultivation temperature to $15-20^{\circ} \mathrm{C}$ (Ong et al., 2008). In general, insoluble proteins are solubilized by use of a high concentration of chaotropic agents or detergents (Singh et al., 2005). Effective solubilization of insoluble proteins requires appropriate chaotropic agents or detergents. To solubilize insoluble proteins, we compared the efficacy of several detergents such as Nonidet P-40 (NP-40), TritonX-100, Tween20, Tween80 and SDS. As a result, except when the cell lysate was treated with SDS, PRV glycoproteins remained in the insoluble fraction (Fig. 6). It is known that SDS is helpful to the solubilization of insoluble protein and its removal required for the refolding of produced protein. However, the use of SDS for solubilization may helpful to the purification step because insoluble protein could not be purified.

When compared with other systems, the expression level of PRV glycoproteins in E. coli was not satisfactory, but more production of $\mathrm{gC}$ and easy and faster expression system have a value to more study. We are currently investigating the purification method of recombinant protein for the development of diagnosis kit or vaccines.

\section{Acknowledgement}

This work was supported by the research grant of the Chungbuk National University in 2011.

\section{References}

Assadi-Porter FM, Patry S, Markley JL (2008) Efficient and rapid protein expression and purification of small high disulfide containing sweet protein brazzein in E. coli. Protein Expr Purif 58(2), 263-268.

Balasch M, Pujols J, Segalés J, Pumarola M (1998) Aujeszky's disease (pseudorabies) virus detection in cerebrospinal fluid in experimentally infected pigs. Vet Microbiol 60(2-4), 99106.

Bane SE, Velasquez JE, Robinson AS (2007) Expression and purification of milligram levels of inactive G-protein coupled receptors in E. coli. Protein Expr Purif 52(2), 348-355.

Burgess-Brown NA, Sharma S, Sobott F, Loenarz C, Oppermann U, Gileadi O (2008) Codon optimization can improve expression of human genes in Escherichia coli: A multigene study. Protein Expr Purif 59(1), 94-102.

Grabowska AK, Lipiñska AD, Rohde J, Szewczyk B, Bienkowska-Szewczyk K, Rziha HJ (2009) New baculovirus recombinants expressing Pseudorabies virus (PRV) glycoproteins protect mice against lethal challenge infection. Vaccine 27(27), 3584-3591.

Hong W, Xiao S, Zhou R, Fang L, He Q, Wu B, Zhou F, Chen $\mathrm{H}$ (2002) Protection induced by intramuscular immunization with DNA vaccines of pseudorabies in mice, rabbits and piglets. Vaccine 20, 1205-1214.

Hsu FS, Lee RC (1984) Use of hyperimmune serum, vaccination, and certain management procedures for control of pseudorabies in swine. J Am Vet Med Assoc 184, 1463-1466.

Katzen F, Peterson TC, Kudlicki W (2009) Membrane protein expression: no cells required. Trends Biotechnol 27(8), 455460.

Kirschner A, Altenbuchner J, Bornscheuer UT (2007) Cloning, expression, and characterization of a Baeyer-Villigermonooxygenase from Pseudomonas fluorescens DSM 50106 in E. coli. Appl Microbiol Biotechnol 73(5), 1065-1072.

Klupp BG, Hengartner CJ, Mettenleiter TC, Enquist LW (2004) Complete, Annotated Sequence of the Pseudorabies Virus Genome. J Virol 78, 424-440.

Koo HN, Bae SM, Choi JB, Shin TY, Yun BNR, Choi JY, Lee KS, Roh JY, Je YH, Jin BR, Yoo SS, Kim JS, Kim YI, Yoon IJ, Woo SD (2011) Characterization and expression of the pseudorabies virus (NYJ strain) glycoproteins in Bombyxmori cells and larvae. J Asia-Pacific Entomol 14, 107-117.

Le PU, Lenferink AE, Pinard M, Baardsnes J, Massie B, O'Connor-McCourt MD (2009) Escherichia coli expression and refolding of E/K-coil-tagged EGF generates fully bioactive EGF for diverse applications. Protein Expr Purif 64(2), 108-117.

Liu YJ, Song FP, He KL, Yuan Y, Zhang XX, Gao P, Wang JH, Wang GY (2004) Expression of a modified Crylle gene in E. coli and in transgenic tobacco confers resistance to corn borer. Acta Biochim Biophys Sin (Shanghai) 36(4), 309-313.

Mettenleiter TC (1994) Pseudorabies (Aujeszky's disease) virus: state of the art. Acta Vet Hung 42(2-3), 153-177. 
Mettenleiter TC (1996) Immunobiology of pseudorabies (Aujeszky's disease). Vet Immunol Immunopathol 54(1-4), 221-229.

Neidhardt EA, Punreddy SR, McLean JE, Hedstrom L, Grossman TH (1999) Expression and characterization of E. coliproduced soluble, functional human dihydroorotate dehydrogenase: a potential target for immunosuppression. J MolMicrobiol Biotechnol 1(1), 183-188.

Ong RM, Goh KM, Mahadi NM, Hassan O, Rahman RN, Illias RM (2008) Cloning, extracellular expression and characterization of a predominant beta-CGTase from Bacillus sp. G1 in E. coli. J Ind Microbiol Biotechnol 35(12), 1705-1714.

Rabhi-Essafi I, Sadok A, Khalaf N, Fathallah DM (2007) A strategy for high-level expression of soluble and functional human interferon a as a GST-fusion protein in E.coli. Protein Eng Des Sel 20(5), 201-209.

Semba H, Ichige E, Imanaka T, Atomi H, Aoyagi H (2008) Efficient production of active form of recombinant cassava hydroxynitrilelyase using Escherichia coli in low-tempera- ture culture. Appl Microbiol Biotechnol 79(4), 563-569.

Singh SM, Panda AK (2005) Solubilization and refolding of bacterial inclusion body proteins. J Biosci Bioeng 99(4), 303-310

Song HS, Lee SH, Oh EH, Park TH (2009) Expression, solubilization and purification of a human olfactory receptor from Escherichia coli. Curr Microbiol 59(3), 309-314.

Sørensen HP, Mortensen KK (2005) Advanced genetic strategies for recombinant protein expression in Escherichia coli. J Biotechnol 115(2), 113-128.

Thakur MK, Ghosh S (2010) GST-tagged mouse estrogen receptor alpha-transactivation domain fusion protein is specifically degraded during its over-expression in E. coli and purification. Mol Biol Rep 37(3), 1335-1440.

Vilnis A, Sussman MD, Thacker BJ, Senn M, Maes RK (1998) Vaccine genotype and route of administration affect pseudorabies field virus latency load after challenge. Vet Microbiol 62(2), 81-96. 